\title{
Current Laser Therapies for the Treatment of Benign Prostatic Hyperplasia
}

\author{
Dr. R. G. Naniwadekar ${ }^{1}$, Dr. Aditya Phadke ${ }^{2}$, Dr. Madhavendra Kabra ${ }^{3}$, Dr. Ujwal Kumar ${ }^{4}$, \\ Dr. Shruti Panicker ${ }^{5}$, Dr. Mahesh Reddy ${ }^{6}$, Dr. Jignesh Savsaviya \\ ${ }^{1}$ Associate Professor, Department of Surgery, Krishna Hospital, Karad, India \\ 2,3, 4, 5, 6,7 Resident, Department of Surgery, Krishna Hospital, Karad, India
}

\begin{abstract}
The gold standard for symptomatic relief of bladder outlet obstruction secondary to be-nign prostatic hyperplasia has traditionally been a transurethral resection of the pros-tate (TURP). Over the past decade, however, novel laser technologies that are patient friendly as compared to the con-ventional TURP have been developed. As part of the ongoing quest to minimize complica-tions, shorten hospitalization, improve resection time, and most importantly reduce mortality, laser prostatectomy has continually evolved. Today, there are more varia-tions of laser prostatectomy, each with several differing surgical techniques. Although abundant data are available confirming the safety and feasibility of the various laser systems, future randomized-controlled trials will be necessary to verify which techni-que is superior. In this article, we describe the most common modalities used to perform a laser prostatectomy, mainly, the holmium laser and the potassium-titanyl-phosphate lasers. We also highlight the physical and clinical characteristics of each technology with a review of their efficacy.
\end{abstract}

Keywords: Laser surgery; Lower urinary tract symptoms; Prostatic hyperplasia; Transurethral prostatectomy

\section{Introduction}

Over the past decade, medical professionals have seen a tremendous growth of lasers used in the treatment of both benign and malignant conditions. Specifically, urologists have witnessed a paradigm shift away from the conventional monopolar transurethral resection of the prostate (TURP) for the treatment of symptomatic BLADDER OUTLET OBSTRUCTION (BOO) toward newer technologies with improved safety yet comparable durability. It is universally accepted that monopolar TURP carries several complications and side effects, including bleeding, fluid absorption, and postoperative electrolyte imbalances. To improve on the pitfalls of conventional TURP, lasers have been used to treat BOO secondary to benign prostatic hyperplasia (BPH). Laser prostatectomy has several advantages over standard TURP, including minimal fluid absorption, technical simplicity, minimal bleeding, and in some cases a shorter duration of hospitalization. Owing to the hemostatic profile of some lasers, laser prostatectomy can even be safely performed in men receiving therapeutic anticoagulation. As such, newer, safer, yet more powerful iterations of various laser fibers continue to evolve, giving the practicing urologist a full armamentarium of laser fibers. In this review, we highlight the variety of lasers currently used to treat BOO and their optical characteristics, which result in differing clinical outcomes.

\section{Types of Lasers Used for Boo}

A host of laser fibers and systems are used to treat BOO. Many of these laser systems use combinations of differing wavelengths to achieve their characteristic properties. The following is a summary of the commercially available la-sers used by urologists [1]:

Coagulative laser: neodymium: yttrium-aluminium-garnet (Nd:YAG), diode laser
Cutting laser: holmium: YAG (Ho:YAG) and thulium: YAG (Tm:YAG)

Vaporizing laser: Nd: YAG, Ho:YAG, diode, KTP (potassium-titanyl-phosphate), and lithium triborate (LBO) Below we summarize the physical properties and clinical outcomes of some of the most widely used laser systems.

\section{Nd:YAG LASER}

One of the first laser systems developed for ablation of prostate adenoma in a procedure later termed "visual ablation of the prostate" (VLAP) is the Nd:YAG laser. This laser emits a 1064-nm wavelength, which is poorly absorbed by water and penetrates deeply into prostatic tissues. In the prostatic tissue, it is converted into thermal energy leading to coagulation, which is one of the system's proposed benefits [2]. Initial results with the $\mathrm{Nd}: \mathrm{YAG}$ laser were promising.

In a nonrandomized trial of VLAP versus conventional TURP, Uchida et al. [3] found that men treated with VLAP had similar clinical outcomes despite lower morbidity rates. One of the largest, multi-institutional randomized trials demonstrated that VLAP required less operative time and resulted in shorter hospitalizations, less bleed-ing, and lower morbidity than did TURP. However, TURP conferred significant and durable improvements in all uri-nary metrics over VLAP [4].

In a more recent multicenter randomized trial, Donovan et al. [5] compared the Nd:YAG laser with standard TURP in more than 200 men. The authors again found TURP to be superior in all primary outcomes in addition to having longer catheterization times compared with the $\mathrm{Nd}: \mathrm{YAG}$ laser.

Ultimately, the popularity of VLAP fell as patients complained of persistent dysuria despite relief of their outlet obstruction, which was likely a result of the dispersive ther- 


\section{International Journal of Science and Research (IJSR) \\ ISSN (Online): 2319-7064}

Index Copernicus Value (2013): 6.14 | Impact Factor (2014): 5.611

mal coagulation effect of this laser [2].

\section{Ho:YAG LASER}

The Ho:YAG laser was first introduced in 1995 by Gilling et al. [6]. This laser emits a 2140-nm wavelength with a depth of penetration less than the Nd:YAG laser of roughly 500 microns [2]. Because this laser is rapidly absorbed by water, it requires contact with the prostate tissue for vaporization to occur, which is a major difference from the KTP laser. The laser system is currently available at a power of up to $100 \mathrm{~W}$. The Ho:YAG laser is also commonly used for the treatment of bladder stones, ureter stones, and upper tract urothelial carcinoma, thus making it extremely versatile. For BOO secondary to $\mathrm{BPH}$, there are two main surgical techniques described that use the holmium laser, each with supportive data.

\section{Holmium laser ablation of the prostate}

This technique, first introduced in 1995, used the 60-W sidefiring Ho:YAG laser to ablate the prostate adenoma in a systematic fashion [6]. Since this time, holmium laser ablation of the prostate (HoLAP) has been evaluated to a lesser degree than its counterpart holmium laser enucleation of the prostate (HoLEP). Whereas HoLAP can ablate prostate tissue effectively while achieving hemostasis, the duration of ablation required to remove large amounts of prostate adenoma was reported to be tedious and costly [7]. Nevertheless, HoLAP has undergone rigorous evaluation.

In a randomized comparison between TURP and HoLAP, Mottet et al. [8] reported the procedure to require more operative time ( 75 minutes vs. 56 minutes); however, it had a shorter catheterization time with equal improvements in patients' International Prostate Symptom Score (IPSS) and maximal urinary flow rate (Qmax). In one of the longest durations of clinical follow-up, Tan et al. [9] found that HoLAP provided durable improvements in urinary metrics up to 7 years postoperatively; however, $15 \%$ of men underwent a repeat transurethral procedure. In men with pros-tate sizes greater than $80 \mathrm{~mL}$, Kumar [10] published data showing HoLAP to be efficacious and feasible with a mean lasing time of 77 minutes. In a comparative trial of HoLAP versus photoselective vaporization of the prostate (PVP), Elzayat et al. [11] reported in a prospective randomized tri-al of 109 men that HoLAP required more operative time (70 minutes vs. 56 minutes).

Today, the 100-W laser system is currently advisable as a safe alternative for smaller prostate glands [7]. Barski et al. [12] reported the most contemporary series of 144 men with a mean prostate volume of $40 \mathrm{~mL}$ by TRUS undergoing $80-$ to $100-\mathrm{W}$ HoLAP. Their mean operative time was 50 minutes with significant improvements in all urinary metrics; however, men with prostate sizes greater than $40 \mathrm{~mL}$ had a reoperation rate of $25 \%$. HoLAP has even been utilized in a "fast-track" ambulatory surgery setting whereby 65 men were discharged directly home with catheters in place. Jumper et al. [13] report there were no readmissions and minimal morbidity within 90 days.

\section{Holmium laser enucleation of the prostate}

In an effort to speed operative time while mimicking the principles of a standard TURP resection, a modification of the ablative technique was first described by Gilling et al. [6] in 1996 and later by Mackey et al. [14] in 1998. Using the laser, the resectionist makes perpendicular incisions in the lateral lobes of the prostate adenoma off the prostatic capsule and later evacuates the prostate chips by means of a morcellator or evacuator. The median lobe is then enucleated back to the verumontanum [15]. This technique allows for retrieval of prostate chips for pathologic tissue analysis.

These reported benefits have generated rigorous evalua-tions into the safety, efficacy, and durability of HoLEP. Gilling et al. [16] reported on 6-year follow-up data for 71 men after HoLEP. This retrospective review represents perhaps the longest experience of HoLEP and demonstrates a satisfaction rate of $92 \%$ with durable improvements in urinary metrics.

For men with large prostates, HoLEP was proven suit-able in two trials comparing HoLEP with open simple prostatectomy. Naspro et al. [17] randomly assigned 80 men with prostates greater than $70 \mathrm{~mL}$ on TRUS and found that whereas simple prostatectomy had a shorter operative time, the men who underwent HoLEP had less bleeding, a lower number of blood transfusions, a shorter catheter-ization time, and a shorter length of hospitalization. At 24 months, the urodynamic and uroflowmetry findings were equal among the groups. In a similar study with a 5-year follow-up of men with prostate sizes greater than $100 \mathrm{~mL}$, Kuntz et al. [18] found equally good results with no statistically significant difference in reoperation rates.

HoLEP has also been reported to be safe in men receiving anticoagulation mediation. Elzayat et al. [19] enrolled 83 men receiving chronic oral anticoagulation therapy with a mean prostate size by TRUS of $82.4 \mathrm{~mL}$ for HoLEP. The authors reported that one patient required intraoperative platelets and 7 men required postoperative blood transfusions; however, there were no major postoperative adverse events or thromboembolic events.

Many comparative trials of the HoLEP technique versus TURP have been performed [20-22]. In one of the first multicenter, prospective randomized trials, Montorsi et al. [23] enrolled 100 men with symptomatic BOO. With routine 1year follow-up, the authors reported equal urodynamic findings and subjective symptom scoring between the HoLEP and TURP groups. The men who underwent HoLEP had a longer operative time but shorter catheter times and hospital lengths of stay. Complications were similar among the groups. In another randomized trial comparing HoLEP with TURP, Ahyai et al. [24] found du-rable improvements in all urinary metrics at 3 years, but the reduction in the postvoid residual (PVR) was sig-nificantly improved in the HoLEP cohort. There were no significant differences in late complication rates of ure-thral strictures, bladder neck contractures, or need for reoperation. In a comparison of the impact of each surgical technique on erectile function, both HoLEP and TURP equally lowered responses on the orgasmic domain of the International Index of Erectile Function questionnaire [25].

Critics of HoLEP report that the procedure is technically challenging and requires at least 20 to 50 cases to gain 


\section{International Journal of Science and Research (IJSR) \\ ISSN (Online): 2319-7064}

Index Copernicus Value (2013): 6.14 | Impact Factor (2014): 5.611

surgical proficiency [2]. The addition of prostatic chip extraction via morcellator adds surgical risk with potential bladder perforations or bladder mucosal injuries being reported [26]. Nevertheless, the holmium laser has been thrust into mainstream use internationally, and despite being technically challenging, HoLEP has been shown to rival the conventional TURP.

\section{KTP AND 532-nm WAVELENGTH LASERS}

Recent advances in laser technologies have allowed for continuous evolution of the KTP lasers. This family of lasers has a 532-nm wavelength that is selectively absorbed by hemoglobin and acts as an intracellular chromophore. Energy is absorbed through a water-based medium into the hemoglobin molecules of the prostate, where it is rapidly heated and causes vaporization of tissue and bubble formation. These unique properties of the 532-nm KTP la-ser allow excellent vaporization while achieving hemostasis with a 1- to 2-mm rim of photocoagulation. As such, the term "photoselective vaporization of the prostate" was coined.

\section{60-W KTP LASER}

The first in vivo report of the 532-nm KTP 60-W laser was in 1998 by Malek et al. [28]. The original prototype was studied in 10 men with $\mathrm{BOO}$ with a mean prostate volume of $38.4 \pm 9.7 \mathrm{~mL}$. In all $10 \mathrm{men}$, Foley catheters were re-moved within 24 hours and maximal urinary flow was sig-nificantly improved. Since this time, numerous studies have been performed evaluating the safety, efficacy, and durability of the $60-\mathrm{W}$ KTP laser. Larger trials performed in 2000 with a 2-year duration of follow-up corroborated the initial findings and moreover demonstrated improvements in American Urological Association Symptom Score (AUASS), Qmax, and PVR [29].

\section{80-W KTP LASER}

While the initial studies of the $60-\mathrm{W}$ KTP laser were promising, perhaps the biggest criticism was a lack of efficient vaporization. To address this, the $80-\mathrm{W}$ KTP laser was introduced to increase the lasing power to accommodate fast-er tissue ablation. To preserve the 1- to 2-mm coagulation zone, a pulsing technology was incorporated that confines the lasing energy solely to the superficial tissues, which is termed "thermal confinement" [2].

The first in vivo human experiments with the $80-\mathrm{W}$ KTP laser demonstrated durable improvements over 1 year in AUASS, Qmax, PVR, and quality of life (QoL) scores [30]. Similar studies with more patients demonstrated equivocal results with low stricture and bladder neck contracture rates (1-2\%) [31-33]. In the first large, multicenter study examining the $80-\mathrm{W}$ KTP laser for the treatment of BOO, Te et al. [34] followed 145 patients over 1 year and found durable improvements in all urinary metrics and significant decreases in prostate volume by ultrasound. No patient required a blood transfusion, and only $3 \%$ had post-operative urinary retention. Next, the $80-\mathrm{W}$ KTP laser was attempted in larger glands (mean prostate volume, $101 \mathrm{~cm}^{3}$ ). Sandhu et al. [35] found no significant difference in preoperative to postoperative serum sodium levels and durable improvements in urinary metrics up to 1 year. Rajbabu et al. [36] performed a similar study in 54 consecutive patients with prostate volumes greater than $100 \mathrm{~mL}$ who were followed for 2 years and reported similar results.

Because the procedure is performed with isotonic saline, the risks of electrolyte imbalance, hyponatremia, and fluid absorption are proposed to be lower. As such, the 80-W KTP laser found a role in high-risk patients with cardiopulmonary risk factors. Men with American Society of Anesthesiology (ASA) scores greater than 3 underwent PVP and at 1 year there were no reported major complications [37]. Chung et al. [38] compiled the largest series of 162 men receiving systemic anticoagulation who underwent 80 W KTP laser prostatectomy. Those authors found an overall 30 -day complication rate of $9 \%$ with a $0 \%$ mortality rate. Only 6 of $162(3.7 \%)$ had delayed bleeding requiring continuous bladder irrigation, and 3 of the $162(1.9 \%)$ required a blood transfusion.

Malek et al. [39] presented long-term follow-up data up to 5 years demonstrating durability with delayed hematuria in 3\% of men and bladder neck contracture in $2 \%$. No patient had urinary incontinence or newly developed impotence, but up to $26 \%$ of the sexually active men experienced retrograde ejaculation. Similarly, Hai [40] in 2009 reported 5-year follow-up data with a reoperation rate of 21 of $249(8.4 \%)$; in that study, bladder neck contracture occurred in 3 patients.

PVP has been associated with minimal change in sexual function with some authors reporting an actual improve-ment in International Index of Erectile Function scores by 7 points [41].

Initial concern about prolonged operative time owing to laser inefficiency leading to increased cost was denounced by Stovsky et al. [42], who found that the estimated cost of PVP was lower than that of microwave therapy, needle ablation, and TURP.

Taken together, these aforementioned studies thrust the 532$\mathrm{nm}$ KTP laser into the spotlight as a major contender with the gold standard TURP. To address this, several head-tohead trials have compared the 532-nm 80-W KTP laser with conventional TURP. Ruszat et al. [43] in 2008 evaluated 396 men assigned to PVP versus TURP in a prospective, nonrandomized two-center study. Those authors found that PVP had a lower rate of intraoperative bleeding, postoperative blood transfusions, capsule perforation, and early postoperative clot retention compared with standard TURP. Furthermore, hospitalization time was shorter in the PVP cohort. Men undergoing TURP demonstrated superior urinary flow rates; however, the IPSS was not significantly different. Reoperation within 2 years was more common in men treated with PVP; however, the difference was not statistically significant. The incidence of urethral and bladder neck strictures was comparable. There have been two randomized trials examining PVP versus TURP. BouchierHayes et al. [44] showed that PVP was equivalent to TURP regarding urinary metrics over 1 year yet had markedly reduced hospital length of stay, duration of catheterization, and postoperative adverse events.

The 80-W KTP laser has rivaled TURP despite conflict-ing results from several randomized clinical trials. It has many theoretical advantages in terms of hemostasis with-out 


\section{International Journal of Science and Research (IJSR) \\ ISSN (Online): 2319-7064}

Index Copernicus Value (2013): 6.14 | Impact Factor (2014): 5.611

absorption of hypotonic fluid. Furthermore, several studies have demonstrated its safety in high-risk patients receiving therapeutic anticoagulation. The main criticism of the $80-\mathrm{W}$ KTP laser is the length of operative time owing to the less than ideal vaporization efficiency.

\section{120-W KTP LASER}

To improve upon vaporization efficiency, the 532-nm 120-W KTP laser was introduced. This new iteration of the hemostatic 532-nm laser used an LBO crystal to better collimate the KTP laser beam. This novel system was termed a "high-performance system" (HPS) [2].

Lee et al. [45] performed the initial animal studies using the 120-W HPS 532-nm laser with 5 male beagle dogs who underwent antegrade PVP following suprapubic cystotomy. The authors compared the $80-\mathrm{W}$ and $120-\mathrm{W}$ lasers and found that the HPS laser consistently vaporized more tissue during a given period while maintaining a 1- to 2-mm rim of coagulation. When comparing the HPS system at $80 \mathrm{~W}$ versus its predecessor at equal wattage, the new HPS system vaporized 50\% more tissue in a bovine ex vivo model [46].

In one of the largest, multicenter, randomized controlled trials comparing the 532-nm 120-W HPS KTP laser with conventional TURP, Lukacs et al. [47] failed to demon-strate the noninferiority of the HPS laser versus TURP on the basis of urinary metrics at 1 year postoperatively. However, the authors did find that PVP was associated with a shorter length of stay in the hospital. In a prospective, randomized trial of 120 men, Al-Ansari et al. [48] found the mean operative time to be shorter for TURP, whereas HPS PVP conferred a shorter hospitalization time and duration of catheterization. The improvements in uri-nary metrics between cohorts were similar; however, the PVP group had a significantly higher number of reoperations. The randomized trial with the longest follow-up actually showed HPS PVP to have a shorter operative time with less intraoperative complications while maintaining a shorter catheterization time and hospital length of stay. After 3 years of follow-up, the urinary metrics between cohorts were similar [49].

The 120-W HPS KTP laser has also been evaluated in select patient populations. For example, in high-risk men with ASA scores greater than 3 and evidence of active cardiopulmonary disease, Tao et al. [50] showed the new 120-W HPS laser to be safe and effective. For men taking blood-thinning medications, Sohn et al. [51] demonstrated that PVP using the HPS laser was safe and effective. For men suffering from urinary retention secondary to advanced prostate cancer, Chen et al. [52] found the HPS laser to be safe and effective, despite being associated with a longer mean catheterization duration ( $3.3 \pm 0.8$ days) for the relief of LUTS secondary to prostate cancer. For men with detrusor underactivity categorized by the Schafer nomo-gram, Choi et al. [53] found that PVP with the HPS laser was effective for relief of $\mathrm{BOO}$ regardless of preexisting de-trusor underactivity.

\section{180-W KTP LASER}

In 2010, the newest edition of KTP 532-nm lasers was approved as the "Xcelerated Performance System" (XPS), which is capable of vaporization up to $180 \mathrm{~W}$. This novel technology, referred to as a MoXy fiber, circulates room temperature saline to prevent devitrification, which may ultimately reduce power. Manufacturers also improved operative time by increasing the rate of vaporization through a $50 \%$ increase in power as well as a $50 \%$ increase in laser beam area. The proposed benefit is wider tissue vaporization without a change in the depth of coagulation (1-2 mm).

The first animal study using the 180-W XPS laser was performed in 2011 on eight canines in an anterograde fashion. Malek et al. [54] found that the 180-W XPS laser created a $76 \%$ larger vaporization cavity and a $77 \%$ faster vaporization rate over the 120 -W HPS laser. The coagulation zone was 33\% larger with the newer model. Mean-while, at 8 weeks postoperatively, the animals had reepithelized resection cavities that were indistinguishable by hematoxylin and eosin staining.

The first prospective human study evaluating safety, efficacy, and perioperative outcomes was performed in 2012. Bachmann et al. [55] prospectively enrolled roughly 200 men with benign prostatic enlargement to undergo $180-\mathrm{W}$ XPS laser prostatectomy at seven different centers worldwide. With a mean follow-up of roughly 6 months, the authors reported significant improvements in IPSS, Qmax, serum prostate-specific antigen level, and prostate volume with no complications higher than IIIb according to the 2004 Clavien-Dindo classification system. Larger randomized controlled trials with over 1 year of follow-up will be necessary to determine if the XPS laser outperforms other transurethral procedures with superior safety and efficacy.

\section{Thulium Laser}

The thulium laser has gained tremendous worldwide popularity since its introduction in 2005. Thulium lasers emit a wavelength of $2013 \mathrm{~nm}$, which permits quick absorption of energy by interstitial water [56]. This addresses some pitfalls of the aforementioned laser fibers because this characteristic wavelength results in matched water ab-sorption with reduced thermal damage owing to its mini-mal penetration depth. The thulium laser allows for either a continuous or a pulsed mode and its energy efficiency pro-file allows it to be a compact, tabletop device suitable for use with any standard $110-\mathrm{V}$ electrical outlet. The technique used with this laser is a combination of vaporization and enucleation until small prostate chips are created and later evacuated. The term "vaporesection" was coined to de-scribe how the thulium laser may resect prostate adenoma while performing concurrent vaporization and ablation. In addition, the laser is also suitable for bladder neck incision [57]. In an ex vivo porcine model, Wendt-Nordahl et al. [58] found that the continuous wave thulium laser offered a higher tissue ablative capacity and similar hemostatic pro-file as did the 80-W KTP laser.

Several studies have shown that the thulium laser pro-vides efficient vaporization in a range of prostate sizes; however, the majority of these series were small and retrospective with limited follow-up $[57,59,60]$. For example, Mattioli et al. [61] used a thulium laser in 200 men stratified by prostate size (less than $35 \mathrm{~g}$ and greater than $35 \mathrm{~g}$ ) and found that regardless of prostate size, the thulium la-ser significantly improved IPSS, uroflowmetry, and PVR, with all patients 


\section{International Journal of Science and Research (IJSR) \\ ISSN (Online): 2319-7064}

Index Copernicus Value (2013): 6.14 | Impact Factor (2014): 5.611

achieving spontaneous voiding without urinary incontinence.

Xia et al. [62] in 2008 randomly assigned 100 men to ei-ther thulium laser resection or conventional TURP. The authors found that the thulium laser was superior in terms of catheterization time, length of stay, and hemoglobin drop. There were no significant differences in operative time, postoperative to preoperative symptom scores, QoL, PVR, or Qmax between the groups. Further randomized, prospective data are lacking comparing the thulium laser with other laser technologies; however, the safety and feasibility of this novel modality are promising. When the thulium laser was compared with HoLEP, Zhang et al. [63] found that thulium laser transurethral enucleation of the prostate (ThuLEP) demonstrated similar relief of lower urinary tract symptoms when compared with HoLEP in a prospective, randomized trial with 18 months of follow-up. ThuLEP was found to have superior hemostasis but longer operative times compared with HoLEP

\section{Diode Lasers}

There are many diode lasers currently on the market with differing wavelengths. Currently, 940-, 980-, and 1470-nm lasers are all available with some packaged as dual-wavelength lasers. There are limited data evaluating diode lasers compared with KTP or holmium lasers, but the results of initial ex vivo studies are promising. Seitz et al. [64] evaluated a 1470-nm diode laser in an isolated, blood perfused porcine kidney model to assess the vaporization and coagulation properties. They compared their diode laser with an 80-W 532-nm KTP laser and found that the diode laser at $50 \mathrm{~W}$ showed significantly lower capacities for tissue removal and larger coagulation zones. The same authors then performed an in vivo study using beagle dogs and found the diode laser to ablate tissue at a rate similar to that of the KTP laser with similar hemostatic properties.

Beyond animal models, there are only a few clinical studies examining diode lasers $[65,66]$. Seitz et al. [67] used a 1470$\mathrm{nm}$ 50-W side-firing diode laser in 10 men and found significant improvements in Qmax, PVR, prostate volume by TRUS, and prostate-specific antigen levels. However, 2 men (20\%) required salvage TURP within 2 months of the initial surgery.

With regard to the 980-nm diode lasers, Leonardi [68] conducted a preliminary study in 52 men and found significant improvement in IPSS, Qmax, and PVR with no severe complications or worsening erectile dysfunction. Ruszat et al. [69] also examined the 980-nm diode laser in a prospective, nonrandomized study with the 120-W 532-nm KTP laser in 117 men. Those authors found improved hemostasis with the diode laser but higher rates of bladder neck stricture, retreatment, and stress urinary incontinence, which was likely due to the penetration depth and coagulation necrosis associated with the diode laser.

In one of the only randomized, prospective studies comparing a $980-\mathrm{nm} 200-\mathrm{W}$ diode laser with the $120-\mathrm{W}$ 532-nm KTP laser in 139 men, Chiang et al. [70] found the diode laser was superior with regard to hemostasis but had high-er rates of postoperative incontinence and dysuria. Both lasers were similar in their rates of improvement of IPSS, Qmax, and QoL.

Perhaps one potential niche of diode lasers that has been studied is outpatient, office-based laser prostatectomy. Rosenthal and DiTrolio [71] reported a small, retrospective series of 200 men who underwent PVP with the Evolve Dual (980-nm/1470-nm) laser system under local periprostatic anesthesia. More recently, the diode laser has been used to perform prostate laser enucleation similar to HoLEP [72]. Bachmann et al. [73] reported in a systematic review an overall paucity of safety and efficacy data for diode lasers with perioperative dysuria in up to $23.6 \%$ of men.

\section{Conclusions}

The ever-changing climate of laser technologies used to treat men with LUTS continues to evolve. Today there are more types of laser fibers than ever before, and urologists remain in a quandary as to which laser technology is superior. Regardless of the type of laser, urologists have come to accept laser prostatectomy as an acceptable alter-native to conventional TURP [74]. Of all the laser prostatectomy techniques, the most robust evaluations have been performed on HoLEP and the 80-W 532-nm KTP-based PVP technique. Although each laser technology has its differences, both technologies are safe, efficacious, and durable and have acceptable morbidity and mortality rates. Detailed guidelines from the European Association of Urology are available for all current laser technologies to help synthesize the most current data beyond that presented in this review [75]. Nevertheless, future random-ized studies comparing the differing laser technologies and surgical techniques are necessary to determine superiority

\section{References}

[1] Rocco B, Albo G, Ferreira RC, Spinelli M, Cozzi G, Dell'orto $\mathrm{P}$, et al. Recent advances in the surgical treatment of benign prostatic hyperplasia. Ther Adv Urol 2011;3:263-72.

[2] Chung DE, Te AE. New techniques for laser prostatectomy: an update. Ther Adv Urol 2009;1:8597.

[3] Uchida T, Egawa S, Iwamura M, Ohori M, Yokoyama E, Endo T, et al. A non-randomized comparative study of visual laser abla-tion and transurethral resection of the prostate in benign pro-static hyperplasia. Int J Urol 1996;3:108-12.

[4] Cowles RS 3rd, Kabalin JN, Childs S, Lepor H, Dixon $\mathrm{C}$, Stein B, et al. A prospective randomized comparison of transurethral re-section to visual laser ablation of the prostate for the treatment of benign prostatic hyperplasia. Urology 1995;46:155-60.

[5] Donovan JL, Peters TJ, Neal DE, Brookes ST, Gujral $\mathrm{S}$, Chacko $\mathrm{KN}$, et al. A randomized trial comparing transurethral resection of the prostate, laser therapy and conservative treatment of men with symptoms associated with benign prostatic enlargement: The CLasP study. J Urol 2000;164:65-70.

[6] Gilling PJ, Cass CB, Cresswell MD, Malcolm AR, Fraundorfer MR. The use of the holmium laser in the treatment of benign pro-static hyperplasia. J Endourol

\section{Volume 5 Issue 2, February 2016}




\section{International Journal of Science and Research (IJSR) \\ ISSN (Online): 2319-7064}

Index Copernicus Value (2013): 6.14 | Impact Factor (2014): 5.611

1996;10:459-61.

[7] Suardi N, Gallina A, Salonia A, Briganti A, Deho F, Zanni $G$, et al. Holmium laser enucleation of the prostate and holmium laser ablation of the prostate: indications and outcome. Curr Opin Urol 2009;19:3843.

[8] Mottet N, Anidjar M, Bourdon O, Louis JF, Teillac P, Costa $\mathrm{P}$, et al. Randomized comparison of transurethral electroresection and holmium: YAG laser vaporization for symptomatic benign pro-static hyperplasia. J Endourol 1999;13:127-30.

[9] Tan AH, Gilling PJ, Kennett KM, Fletcher H, Fraundorfer MR. Long-term results of high-power holmium laser vaporization (ablation) of the prostate. BJU Int 2003;92:707-9.

[10] Kumar SM. Rapid communication: holmium laser ablation of large prostate glands: an endourologic alternative to open prostatectomy. J Endourol 2007;21:659-62.

[11] Elzayat EA, Al-Mandil MS, Khalaf I, Elhilali MM. Holmium laser ablation of the prostate versus photoselective vaporization of prostate $60 \mathrm{cc}$ or less: short-term results of a prospective random-ized trial. J Urol 2009;182:133-8.

[12] Barski D, Richter M, Winter C, Arsov C, de Geeter P, Rabenalt $\mathrm{R}$, et al. Holmium laser ablation of the prostate (HoLAP): inter-mediate-term results of 144 patients. World J Urol 2012 Jul 11 [Epub]. http://dx.doi.org/10.1007/s00345-012-0901-6.

[13] Jumper C, Snyder P, Yap RL. Rapid ambulatory pathway laser prostatectomy is safe: results within the global period. BJU Int 2012;110:1190-3.

[14] Mackey MJ, Chilton CP, Gilling PJ, Fraundorfer M, Cresswell MD. The results of holmium laser resection of the prostate. Br J Urol 1998;81:518-9.

[15] Son H, Song SH, Paick JS. Current laser treatments for benign prostatic hyperplasia. Korean J Urol 2010;51:737-44.

[16] Gilling PJ, Aho TF, Frampton CM, King CJ, Fraundorfer MR. Holmium laser enucleation of the prostate: results at 6 years. Eur Urol 2008;53:744-9.

[17] Naspro R, Suardi N, Salonia A, Scattoni V, Guazzoni $\mathrm{G}$, Colombo R, et al. Holmium laser enucleation of the prostate versus open prostatectomy for prostates $>70$ g: 24-month follow-up. Eur Urol 2006;50:563-8.

[18] Kuntz RM, Lehrich K, Ahyai SA. Holmium laser enucleation of the prostate versus open prostatectomy for prostates greater than 100 grams: 5-year follow-up results of a randomised clinical trial. Eur Urol 2008;53:160-6.

[19] Elzayat E, Habib E, Elhilali M. Holmium laser enucleation of the prostate in patients on anticoagulant therapy or with bleeding disorders. J Urol 2006; 175:1428-32.

[20] Rigatti L, Naspro R, Salonia A, Centemero A, Ghezzi M, Guazzoni G, et al. Urodynamics after TURP and HoLEP in urodynamically obstructed patients: are there any differences at 1 year of fol-low-up? Urology 2006;67:1193-8.

[21] Wilson LC, Gilling PJ, Williams A, Kennett KM, Frampton CM, Westenberg AM, et al. A randomised trial comparing holmium la-ser enucleation versus transurethral resection in the treatment of prostates larger than 40 grams: results at 2 years. Eur Urol 2006;50:569-73.

[22] Mavuduru RM, Mandal AK, Singh SK, Acharya N, Agarwal M, Garg S, et al. Comparison of HoLEP and TURP in terms of efficacy in the early postoperative period and perioperative morbidity. Urol Int 2009;82:130-5.

[23] Montorsi F, Naspro R, Salonia A, Suardi N, Briganti A, Zanoni $\mathrm{M}$, et al. Holmium laser enucleation versus transurethral re-section of the prostate: results from a 2center prospective randomized trial in patients with obstructive benign prostatic hyperplasia. J Urol 2008;179(5 Suppl):S87-90.

[24] Ahyai SA, Lehrich K, Kuntz RM. Holmium laser enucleation ver-sus transurethral resection of the prostate: 3-year follow-up re-sults of a randomized clinical trial. Eur Urol 2007;52:1456-63.

[25] Briganti A, Naspro R, Gallina A, Salonia A, Vavassori I, Hurle R, et al. Impact on sexual function of holmium laser enucleation ver-sus transurethral resection of the prostate: results of a pro-spective, 2-center, randomized trial. J Urol 2006;175:1817-21.

[26] Shah HN, Mahajan AP, Hegde SS, Bansal MB. Perioperative complications of holmium laser enucleation of the prostate: expe-rience in the first 280 patients, and a review of literature. BJU Int 2007;100:94-101.

[27] Lee R, Gonzalez RR, Te AE. The evolution of photoselective vapor-ization prostatectomy (PVP): advancing the surgical treatment of benign prostatic hyperplasia. World J Urol 2006;24:405-9.

[28] Malek RS, Barrett DM, Kuntzman RS. High-power potassium-ti-tanyl-phosphate $(\mathrm{KTP} / 532)$ laser vaporization prostatectomy: 24 hours later. Urology 1998;51:254-6.

[29] Malek RS, Kuntzman RS, Barrett DM. High power potassium-ti-tanyl-phosphate laser vaporization prostatectomy. J Urol 2000;163:1730-3.

[30] Hai MA, Malek RS. Photoselective vaporization of the prostate: initial experience with a new $80 \mathrm{~W}$ KTP laser for the treatment of benign prostatic hyperplasia. J Endourol 2003;17:93-6.

[31] Araki M, Lam PN, Wong C. High-power potassiumtitanyl-phos-phate laser photoselective vaporization prostatectomy for symp-tomatic benign prostatic hyperplasia. J Endourol 2008;22: 1311-4.

[32] Volkan T, Ihsan TA, Yilmaz O, Emin O, Selcuk S, Koray K, et al. Short term outcomes of high power (80 W) potassium-titanyl-pho-sphate laser vaporization of the prostate. Eur Urol 2005;48: 608-13.

[33] Tugcu V, Tasci AI, Sahin S, Ordekci Y, Karakas OF, Zorluoglu F. Outcomes of 80 W KTP laser vaporization of the large prostate. Urol Int 2007;79:316-20.

[34] Te AE, Malloy TR, Stein BS, Ulchaker JC, Nseyo UO, Hai MA, et al. Photoselective vaporization of the prostate for the treatment of benign prostatic hyperplasia: 12-month results from the first United States multicenter prospective trial. J Urol 2004;172(4 Pt 1):1404-8.

[35] Sandhu JS, Ng C, Vanderbrink BA, Egan C, Kaplan SA, Te AE. High-power potassium-titanyl-phosphate photoselective laser vaporization of prostate for treatment of benign prostatic hyper-plasia in men with 


\section{International Journal of Science and Research (IJSR) \\ ISSN (Online): 2319-7064}

Index Copernicus Value (2013): 6.14 | Impact Factor (2014): 5.611

large prostates. Urology 2004;64:1155-9.

[36] Rajbabu K, Chandrasekara SK, Barber NJ, Walsh K, Muir GH. Photoselective vaporization of the prostate with the potassium-ti-tanyl-phosphate laser in men with prostates of $>100 \mathrm{~mL}$. BJU Int 2007;100:593-8.

[37] Reich O, Bachmann A, Siebels M, Hofstetter A, Stief CG, Sulser T. High power $(80 \mathrm{~W})$ potassium-titanylphosphate laser vapor-ization of the prostate in 66 high risk patients. J Urol 2005; 173: 158-60.

[38] Chung DE, Wysock JS, Lee RK, Melamed SR, Kaplan SA, Te AE. Outcomes and complications after $532 \mathrm{~nm}$ laser prostatectomy in anticoagulated patients with benign prostatic hyperplasia. J Urol 2011;186:977-81.

[39] Malek RS, Kuntzman RS, Barrett DM. Photoselective potas-sium-titanyl-phosphate laser vaporization of the benign ob-structive prostate: observations on long-term outcomes. J Urol 2005;174(4 Pt 1):1344-8.

[40] Hai MA. Photoselective vaporization of prostate: fiveyear out-comes of entire clinic patient population. Urology 2009;73:807-10.

[41] Paick JS, Um JM, Kim SW, Ku JH. Influence of highpower potas-sium-titanyl-phosphate photoselective vaporization of the pros-tate on erectile function: a short-term follow-up study. J Sex Med 2007;4:1701-7.

[42] Stovsky MD, Griffiths RI, Duff SB. A clinical outcomes and cost analysis comparing photoselective vaporization of the prostate to alternative minimally invasive therapies and transurethral pros-tate resection for the treatment of benign prostatic hyperplasia. J Urol 2006;176(4 Pt 1):1500-6.

[43] Ruszat R, Wyler SF, Seitz M, Lehmann K, Abe C, Bonkat G, et al. Comparison of potassium-titanylphosphate laser vapor-ization of the prostate and transurethral resection of the prostate: update of a prospective non-randomized two-centre study. BJU Int 2008;102:1432-8.

[44] Bouchier-Hayes DM, Van Appledorn S, Bugeja P, Crowe H, Challacombe B, Costello AJ. A randomized trial of photoselective vaporization of the prostate using the $80-\mathrm{W}$ potassium-ti-tanyl-phosphate laser vs transurethral prostatectomy, with a 1-year follow-up. BJU Int 2010;105:964-9.

[45] Lee R, Saini R, Zoltan E, Te AE. Photoselective vaporization of the prostate using a laser high performance system in the canine model. J Urol 2008;180:1551-3.

[46] Kang HW, Jebens D, Malek RS, Mitchell G, Koullick E. Laser va-porization of bovine prostate: a quantitative comparison of potas-sium-titanyl-phosphate and lithium triborate lasers. J Urol 2008;180:2675-80.

[47] Lukacs B, Loeffler J, Bruyere F, Blanchet P, Gelet A, Coloby $\mathrm{P}$, et al. Photoselective vaporization of the prostate with GreenLight 120-W laser compared with monopolar transurethral resection of the prostate: a multicenter randomized controlled trial. Eur Urol 2012;61:1165-73.

[48] Al-Ansari A, Younes N, Sampige VP, Al-Rumaihi K, Ghafouri A, Gul T, et al. GreenLight HPS 120-W laser vaporization versus transurethral resection of the prostate for treatment of benign prostatic hyperplasia: a randomized clinical trial with midterm follow-up. Eur Urol 2010;58:349-55.

[49] Xue B, Zang Y, Zhang Y, Yang D, Gao J, Sun C, et al.
GreenLight HPS 120-W laser vaporization versus transurethral resection of the prostate for treatment of benign prostatic hyperplasia: a pro-spective randomized trial. J Xray Sci Technol 2013;21:125-32.

[50] Tao W, Xue B, Zang Y, Sun C, Yang D, Zhang Y, et al. The applica-tion of 120-W high-performance system GreenLight laser vapor-ization of the prostate in highrisk patients. Lasers Med Sci 2012 Oct 4 [Epub]. http://dx.doi.org/10.1007/s10103-012-1212-2.

[51] Sohn JH, Choi YS, Kim SJ, Cho HJ, Hong SH, Lee JY, et al. Effectiveness and safety of photoselective vaporization of the prostate with the 120 W HPS Greenlight laser in benign prostatic hyperplasia patients taking oral anticoagulants. Korean J Urol 2011;52:17883.

[52] Chen D, Xue B, Shan Y, Yang D, Sun C, Gao J. GreenLight HPS 120-W laser photoselective vaporization of the prostate as ear-ly therapy for acute urinary retention in advanced prostate cancer patients. Lasers Med Sci 2013 Jan 3 [Epub]. http://dx.doi.org/10.1007/s10103-012-1252-7

[53] Choi SW, Choi YS, Bae WJ, Kim SJ, Cho HJ, Hong $\mathrm{SH}$, et al. $120 \mathrm{~W}$ Greenlight HPS laser photoselective vaporization of the pros-tate for treatment of benign prostatic hyperplasia in men with de-trusor underactivity. Korean J Urol 2011;52:824-8.

[54] Malek RS, Kang HW, Peng YS, Stinson D, Beck MT, Koullick E. Photoselective vaporization prostatectomy: experience with a novel 180 W 532 nm lithium triborate laser and fiber delivery sys-tem in living dogs. J Urol 2011;185:712-8.

[55] Bachmann A, Muir GH, Collins EJ, Choi BB, Tabatabaei S, Reich OM, et al. 180-W XPS GreenLight laser therapy for benign pros-tate hyperplasia: early safety, efficacy, and perioperative out-come after 201 procedures. Eur Urol 2012;61:600-7.

[56] Fried NM, Murray KE. High-power thulium fiber laser ablation of urinary tissues at 1.94 microm. J Endourol 2005; 19:25-31.

[57] Bach T, Herrmann TR, Ganzer R, Burchardt M, Gross AJ. RevoLix vaporesection of the prostate: initial results of 54 pa-tients with a 1-year follow-up. World J Urol 2007;25:257-62.

[58] Wendt-Nordahl G, Huckele S, Honeck P, Alken P, Knoll T, Michel MS, et al. Systematic evaluation of a recently introduced 2-mi-crom continuous-wave thulium laser for vaporesection of the prostate. J Endourol 2008;22:1041-5.

[59] Bach T, Wendt-Nordahl G, Michel MS, Herrmann TR, Gross AJ. Feasibility and efficacy of Thulium:YAG laser enucleation (VapoEnucleation) of the prostate. World J Urol 2009;27:541-5.

[60] Bach T, Herrmann TR, Ganzer R, Blana A, Burchardt M, Gross AJ. Thulium:YAG vaporesection of the prostate. First results. Urologe A 2009;48:529-34.

[61] Mattioli S, Munoz R, Recasens R, Berbegal C, Cortada $\mathrm{J}$, Urmeneta JM, et al. Treatment of benign prostatic hyperplasia with the Revolix laser. Arch Esp Urol 2008;61:1037-43.

[62] Xia SJ, Zhuo J, Sun XW, Han BM, Shao Y, Zhang YN. Thulium laser versus standard transurethral resection of the prostate: a randomized prospective trial. Eur Urol 2008;53:382-89.

\section{Volume 5 Issue 2, February 2016}


[63] Zhang F, Shao Q, Herrmann TR, Tian Y, Zhang Y. Thulium laser versus holmium laser transurethral enucleation of the prostate: 18-month follow-up data of a single center. Urology 2012;79: 869-74.

[64] Seitz M, Ruszat R, Bayer T, Tilki D, Bachmann A, Stief $C$, et al. Ex vivo and in vivo investigations of the novel $1,470 \mathrm{~nm}$ diode laser for potential treatment of benign prostatic enlargement. Lasers Med Sci 2009;24:419-24.

[65] Erol A, Cam K, Tekin A, Memik O, Coban S, Ozer Y. High power diode laser vaporization of the prostate: preliminary results for benign prostatic hyperplasia. J Urol 2009;182:1078-82.

[66] Yang KS, Seong YK, Kim IG, Han BH, Kong GS. Initial experi-ences with a $980 \mathrm{~nm}$ diode laser for photoselective vaporization of the prostate for the treatment of benign prostatic hyperplasia. Korean $\mathrm{J}$ Urol 2011;52:752-6.

[67] Seitz M, Sroka R, Gratzke C, Schlenker B, Steinbrecher V, Khoder W, et al. The diode laser: a novel side-firing approach for laser va-porisation of the human prostate--immediate efficacy and 1-year followup. Eur Urol 2007;52:1717-22.

[68] Leonardi R. Preliminary results on selective light vaporization with the side-firing $980 \mathrm{~nm}$ diode laser in benign prostatic hyper-plasia: an ejaculation sparing technique. Prostate Cancer Pros-tatic Dis 2009;12:27780.

[69] Ruszat R, Seitz M, Wyler SF, Muller G, Rieken M, Bonkat $\mathrm{G}$, et al. Prospective single-centre comparison of $120-\mathrm{W}$ diode-pumped solid-state high-intensity system laser vaporization of the pros-tate and $200-\mathrm{W}$ high-intensive diode-laser ablation of the prostate for treating benign prostatic hyperplasia. BJU Int 2009; 104: 820-5.

[70] Chiang $\mathrm{PH}$, Chen $\mathrm{CH}$, Kang $\mathrm{CH}$, Chuang $\mathrm{YC}$. GreenLight HPS laser 120-W versus diode laser 200-W vaporization of the pros-tate: comparative clinical experience. Lasers Surg Med 2010;42: 624-9.

[71] Rosenthal BD, DiTrolio JV. Photoselective vaporization of the prostate in office and outpatient settings. Can J Urol 2012;19: 6223-6.

[72] Buisan O, Saladie JM, Ruiz JM, Bernal S, Bayona S, Ibarz L. Diode laser enucleation of the prostate (Dilep): technique and ini-tial results. Actas Urol Esp 2011;35:37-41.

[73] Bachmann A, Woo HH, Wyler S. Laser prostatectomy of lower uri-nary tract symptoms due to benign prostate enlargement: a crit-ical review of evidence. Curr Opin Urol 2012;22:22-33.

[74] Hoffman RM, MacDonald R, Wilt TJ. Laser prostatectomy for be-nign prostatic obstruction. Cochrane Database Syst Rev 2004;(1): CD001987.

[75] Herrmann TR, Liatsikos EN, Nagele U, Traxer O, Merseburger AS; EAU Guidelines Panel on Lasers, Technologies. EAU guide-lines on laser technologies. Eur Urol 2012;61:783-95. 